\title{
MEMAHAMI URBAN SPRAWL: ANALISA PERKEMBANGAN PERMUKIMAN KOTA SALATIGA DENGAN DIGITASI ARCGIS
}

\author{
Ma'rifatun Khasanah \\ Program Studi Arsitektur, Universitas Muhammadiyah Surakarta \\ risreafana@gmail.com

\section{Dyah Widi Astuti} \\ Program Studi Arsitektur, Universitas Muhammadiyah Surakarta \\ dyahwidi.dw@gmail.com
}

Naskah diajukan pada: 12 Agustus 2020

Naskah revisi akhir diterima pada: 09 September 2020

\begin{abstract}
Abstrak
Pembangunan infrastruktur di Salatiga semakin meningkat, tidak hanya untuk keperluan aksesibilitas tapi juga karena semakin bertambahnya jumlah penduduk kota, baik penduduk asli maupun pendatang. Pembangunan tersebut juga dilakukan untuk memeratakan kegiatan ekonomi agar tidak tersentral di pusat kota. Contohnya adalah dibangunnya Jalan Lingkar Selatan (JLS) Salatiga yang memberikan dampak ekonomi, sosial, dan aksesibilitas terhadap perkembangan di daerah selatan kota karena melewati tiga kecamatan. Untuk mencegah perkembangan tidak terkendali yang akan timbul maka diperlukanlah kontrol perencanaan pembangunan di kawasan pinggiran tersebut. Penelitian ini mengambil satu contoh perumahan di setiap kecamatan yang berada di perbatasan Salatiga, yaitu Kecamatan Sidorejo (P1), Kecamatan Sidomukti (P2), Kecamatan Argomulyo (P3), dan Kecamatan Tingkir (P4). Metode yang digunakan adalah digitasi menggunakan software ArcGIS, sebagai alat bantu untuk memetakan kawasan perumahan sehingga bisa terlihat titik mana yang mengalami perkembangan paling pesat yang berpotensi menyebabkan terjadinya urban sprawl. Dari hasil digitasi tersebut terlihat titik yang mengalami perkembangan paling pesat adalah P3, dengan faktor preferensi bermukim paling banyak dikarenakan perumahan memiliki harga murah. Hal ini memungkinkan terjadinya urban sprawl di masa datang dengan berkembangnya infrastruktur yang semakin baik, dekat dengan fasilitas pelayanan umum seperti sekolah, kesehatan, keamanan, hiburan dan kemudahan aksesibilitas berupa jalur angkutan umum di titik tersebut.
\end{abstract}

Kata-kata Kunci: Arsitektur Kota, Urban Sprawl, Permukiman

\section{UNDERSTANDING THE URBAN SPRAWL: ANALYSIS RESIDENTAL DEVELOPMENT IN SALATIGA CITY WITH ARCGIS}

\begin{abstract}
Infrastructure development at Salatiga is increasing, not only for needing accessibility but also for the growing urban population, both the natives and settlers. Such development is also being used to flatten economic activities not centralized in the urban core. An example is the development of Jalan Lingkar Selatan (JLS) Salatiga that has impact in economy, social, and accessibility for growth in the southern city of the city through three subdistricts. To prevent these uncontrolled
\end{abstract}


developments requires control in building planning in the suburban. The study takes one sample housing in every district located on the Salatiga suburban, and those are Sidorejo district (P1), Sidomukti district (P2), Argomulyo district (P3), and Tingkir district (P4). The method used is digitized using ArcGIS software to map the region, so it can see which point is experiencing the most rapid growth that potentially causes urban sprawl. From that digitization, the most developed node is P3, with the most preference factor of settling because housing is cheap. It allows urban sprawl in the future with better infrastructure increase, near a public service facility like school, health, security, entertainment, and easiness accessibility such as public transport routes in this node.

\section{Keywords: Urban Architecture, Urban Sprawl, Settlements}

\section{Pendahuluan}

Kota Salatiga berada di antara dua kota besar yaitu Kota Semarang dan Kota Surakarta, yang menyebabkan Salatiga menjadi jalur perlintasan antar kota. Hal ini menyebabkan pembangunan infrastruktur di Salatiga semakin meningkat, tidak hanya untuk keperluan aksesibilitas tapi juga karena semakin bertambahnya jumlah penduduk kota, baik penduduk asli maupun pendatang. Pembangunan tersebut juga dilakukan untuk memeratakan kegiatan ekonomi agar tidak tersentral di pusat kota. Contohnya adalah dibangunnya Jalan Lingkar Selatan (JLS) Salatiga yang memberikan dampak ekonomi, sosial, dan aksesibilitas terhadap perkembangan di daerah selatan kota karena melewati tiga kecamatan.

Kebutuhan akan hunian dan pembangunan perumahan dalam jangka waktu dua dekade ini berkembang cukup pesat. Dari perkembangan spasial tersebut memunculkan ciri fenomena urban sprawl, yang disarikan dari Hardari (2011), bisa didefinisikan dengan berkembangnya daerah rural menjadi daerah urban (bersifat kekotaan), biasanya memiliki ciri perubahan lahan non terbangun menjadi lahan terbangun. Menurut Apriani dan Asnawi (2015), kawasan perbatasan paling berpotensi terkena dampak ekspansi sprawl karena masih memiliki banyak lahan non terbangun yang bisa dikembangkan menjadi perumahan. Sejalan dengan penjelasan Rafferty (2019), bahwa sprawl menyebabkan pertumbuhan ekonomi dan infrastruktur dalam suatu wilayah, namun berpotensi merusak lahan alami. Untuk mencegah perkembangan tidak terkendali tersebut maka diperlukanlah kontrol perencanaan pembangunan di kawasan pinggiran.

Pengamatan terhadap perkembangan permukiman dapat dilakukan dengan pengamatan secara fisik melalui citra satelit dengan rentang waktu tertentu. Perbedaan rentang waktu inilah yang nantinya dikomparasikan agar terlihat pola perkembangannya, kemudian dilakukan analisa untuk mengetahui faktor apa yang mempengaruhi perkembangan di kawasan tersebut. Hasil analisis perkembangan permukiman ini diharapkan mampu membantu pemerintah dalam proses pemerataan kegiatan ekonomi dalam kota dengan membangun fasilitas yang tepat guna, dan mengurangi dampak urban sprawl di kawasan sub-urban lainnya.

\section{Perkembangan Kota}

Kota secara definisi memiliki pengertian yang berbeda, dilihat dari pendekatan dan sudut pandang ilmu yang digunakan. Pemahaman kota dalam arsitektur dilihat dari prasarana dan pembangunan struktur anatomi kota yang memperhatikan hubungan antara ruang dan massa perkotaan; bentuk dan pola; serta bagaimana semua itu dapat terkait. Zahnd (2006) merumuskan sebuah kota bukan dari ciri morfologisnya, melainkan segi fungsi khusus - yaitu menyusun sebuah wilayah dan menciptakan ruang efektif melalui pengorganisasian daerah pedalaman yang lebih besar berdasarkan hirarki tertentu.

Kota sebagai suatu lingkungan fisik mempunyai aspek yang bisa mengembangkan, mengangkat, dan menciptakan karakteristik kota itu sendiri, seperti aspek sejarah, budaya, geografis, 
dan hal faktual yang memberikan identitas kota. Identitas kota menurut Kevin Lynch (dalam Krismanto, 2018) adalah sebuah sense of place, dimana seseorang dapat mengingat atau menyadari suatu tempat yang berkarakter jelas, unik, dan khas.

Perkembangan kota sangat beragam jika diamati dari tinjauan historisnya. Proses evolusinya sangat dipengaruhi dan ditentukan oleh faktor peradaban dan kebudayaan, teknologi, tuntutan kebutuhan, dan komunikasi pendukungnya. Bentuk, fungsi, dan penampilan kota baru yang dikembangkan kemudian pada masa tertentu merupakan upaya perbaikan dan pengembangan kota baru pada masa sebelumnya. Kekhususan yang dapat membedakan kota-kota baru di Indonesia dengan negara industri maju terutama adalah keunikan pola masyarakat, kegiatan usahanya, dan sistem politik kelembagaan yang dianut dan terjewantahkan dalam unsur-unsur lingkungan fisik. Hal tersebut kemudian menjadi dasar dalam perkembangan selanjutnya (Budihardjo \& Sujarto, 2009).

\section{Faktor Preferensi Bermukim}

Preferensi bermukim merupakan kecenderungan seseorang untuk membuat keputusan bermukim atau tidak. Faktor penyebabnya berbeda antara orang yang satu dan lainnya. Menurut Turner, 1977 dalam Housing by People: Towards Autonomy in Building Environment, konsep prioritas bermukim disebabkan oleh beberapa faktor yang dipengaruhi oleh tingkat pendapatan penghuni (Gambar 1). Seperti faktor keamanan, identity, standar hunian, dan hak kepemilikan rumah. Bagi masyarakat berpenghasilan rendah yang menjadi prioritas mereka adalah opportunity atau kemudahan dalam mendapatkan akses pekerjaan, interaksi sosial dan budaya. Untuk masyarakat berpenghasilan menengah, faktor preferensi bermukimnya karena keamanan, hak kepemilikan hunian, dan hunian standar modern. Sedangkan untuk masyarakat berpenghasilan tinggi, faktor preferensinya terkait dengan identity (kualitas hunian dalam melindungi penghuninya) dan hunian standar modern.

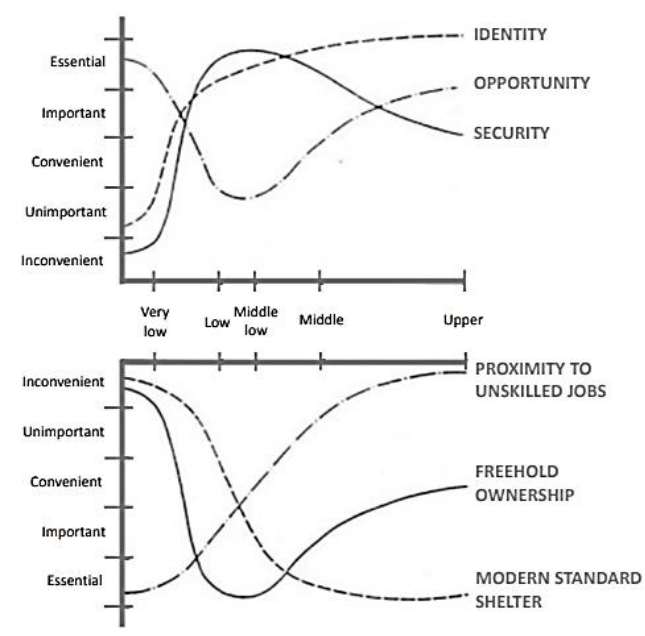

Gambar 1. Prioritas Bermukim oleh Turner Sumber: Turner, 1977

Menurut Christiansen \& Loftsgarden (2011) dalam beberapa studi di Eropa, pertumbuhan populasi bukan lagi faktor penentu dari urban sprawl. Sebaliknya faktor budaya dan preferensi bermukim tiap individu terkait faktor ekonomi (kekuatan pasar, harga rumah, dan biaya transportasi) lebih banyak mempengaruhi perkembangan. Faktor budaya dan preferensi bermukim ini juga dipengaruhi oleh proses pembangunan perkotaan dan perubahan penduduk. Faktor preferensi bagi mereka yang pindah ke perbatasan kota atau tidak itu sama, yaitu terkait dengan keamanan dan 
lingkungan yang tenang. Selain itu pendapatan individu merupakan faktor penting yang mengatur preferensi bermukim.

Menurut Drabkin (dalam Paruntung, 2004) beberapa faktor yang mempengaruhi pemilihan lokasi perumahan yang secara individu saling berbeda, antara lain: 1) aksesibilitas, yang terdiri dari jarak dan kemudahan transportasi ke pusat kota; 2) lingkungan, yang terdiri dari lingkungan sosial dan fisik seperti kebisingan, polusi dan kenyamanan lingkungan; 3) peluang kerja yang tersedia, berupa kemudahan seseorang dalam mendapatkan pekerjaan untuk kebutuhan hidupnya, 4) tingkat pelayanan, lokasi yang dipilih merupakan lokasi yang memiliki pelayanan yang baik dalam hal sarana dan prasarana, dan lain-lain.

Menurut Yusuf (dalam Kharisma et al. 2017) pilihan masyarakat memilih hunian perumahan di pinggiran kota didasari karena alasan biaya atau harga rumah yang ditawarkan cenderung murah. Dengan harga rumah yang relatif murah menjadikan daya tarik bagi masyarakat untuk memilih tinggal di pinggiran kota.

\section{Urban Sprawl}

Urban sprawl disebut juga sprawl atau suburban sprawl, adalah perluasan yang cepat dari jangkauan geografis kota dan sering ditandai dengan perumahan dengan kepadatan rendah, zonasi sekali pakai, dan peningkatan ketergantungan pada kendaraan pribadi untuk transportasi. Sprawl sering dihubungkan dengan meningkatnya penggunaan energi, polusi, kemacetan lalu lintas dan penurunan karakteristik sosial masyarakat (Rafferty, 2019).

Urban Sprawl merupakan permukiman yang tidak direncanakan oleh pihak terkait (di Indonesia oleh pemerintah) akan muncul di suatu kawasan. Alasan munculnya sprawl ini secara kasat mata adalah meningkatnya jumlah penduduk asli maupun pendatang (urbanisasi) yang membutuhkan hunian dengan kualitas baik dan akses cepat menuju tempat kerja. Selain itu pemenuhan hunian yang murah juga menjadi faktor lain dari munculnya sprawl. Hal ini secara tidak langsung dapat menimbulkan berkurangnya lahan hijau dan perubahan fungsi lahan di suatu kota.

Akibat lain yang ditimbulkan dari sprawl adalah berkembangnya kegiatan ekonomi di daerah sekitar karena aspek pemenuhan kebutuhan penghuni. Pembentukan jalan baru atau perbaikan jalan juga berpotensi meningkatkan aksesibilitas penghuni antar kawasan sehingga membentuk lingkungan dan kegiatan sosial yang baru.

\section{Metode}

Meninjau jenis penelitian yang relevan dengan penelitian bidang perumahan dan permukiman menurut Darjosanjoto (2006), penelitian yang akan dilakukan ini termasuk sebagai penelitian korelasional. Sedangkan cara yang digunakan adalah pengamatan terhadap akibat yang ada dan mencari faktor apa yang menjadi penyebab melalui data tertentu. Menurut jenis data dan analisnya, penelitian ini merupakan penelitian kualitatif. Data kualitatif adalah data dalam bentuk kata, kalimat dan gambar. Sehingga dalam penyampaian analisis dan pembahasannya dilakukan secara deskriptif (Sukmadinata dalam Muthmainnah, 2018).

\section{Fokus Penelitian}

\section{A. Sampling}

Pemilihan empat lokasi dengan perbedaan rentang tahun yang cukup panjang yaitu tahun 2002, 2010, dan 2019. Kecuali lokasi P4, data tahun 2010 menggunakan data tahun 2012, dikarenakan data tidak bisa disinkronkan. 


\section{B. Lokasi}

Penelitian ini berfokus pada keterkaitan perkembangan perumahan dengan fasilitas sarana prasarana dan infrastruktur di sekitar kawasan perumahan tersebut. Pemilihan obyek penelitian dipilih berdasarkan lokasi perumahan yang dekat dengan perbatasan kota dan cukup jauh dari pusat kota (titik nol). Setiap lokasi berikut mewakili satu kecamatan dalam kota. Lokasi tersebut dapat diuraikan sebagai berikut (Gambar 2): Perumahan Manunggal 2 di Kecamatan Sidorejo (P1); Perumahan PNS Prajamukti di Kecamatan Sidomukti (P2); Perumahan PNS Prajamulya di Kecamatan Argomulyo (P3); dan Perumahan Taman Mutiara di Kecamatan Tingkir (P4).

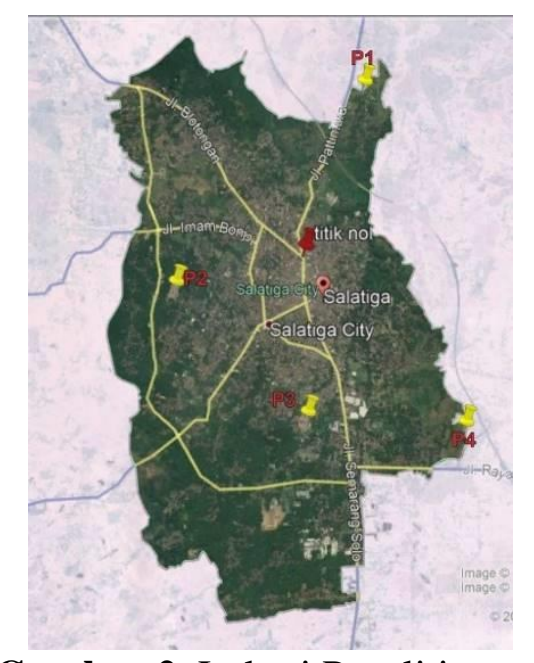

Gambar 2. Lokasi Penelitian

Sumber: Google Earth, 2019

\section{Instrumen Penelitian}

\section{A. Dokumentasi}

Digitasi data citra satelit menggunakan software ArcGIS, untuk memudahkan dalam proses pembuatan peta perkembangan yang proporsional. ArcGIS merupakan perangkat lunak berbasis sistem informasi geografis (SIG) yang memiliki lima tingkat lisensi. Digitasi ini menggunakan ArcMap yang merupakan aplikasi utama untuk pemetaan menggunakan komputer. ArcMap mampu memvisualisasikan, membuat database, analisis dan membuat tampilan akhir peta untuk laporan-laporan.

\section{B. Kuesioner}

Berdasarkan pada teori preferensi bermukim di atas, dibuatlah kuesioner sebanyak 13 nomor dengan poin terkait dengan: jumlah penghuni; asal daerah; alasan tinggal; aksesibilitas menuju sekolah, tempat kerja, dan hiburan; serta kenyamanan hunian dan lingkungannya. Sampling setiap perumahan diambil lima rumah secara acak. Data dari penghuni perumahan tersebut diakumulasikan dalam bentuk diagram sehingga diperoleh faktor umum yang mempengaruhi penghuni dalam memilih hunian. 


\section{Alur Pikir Penelitian}

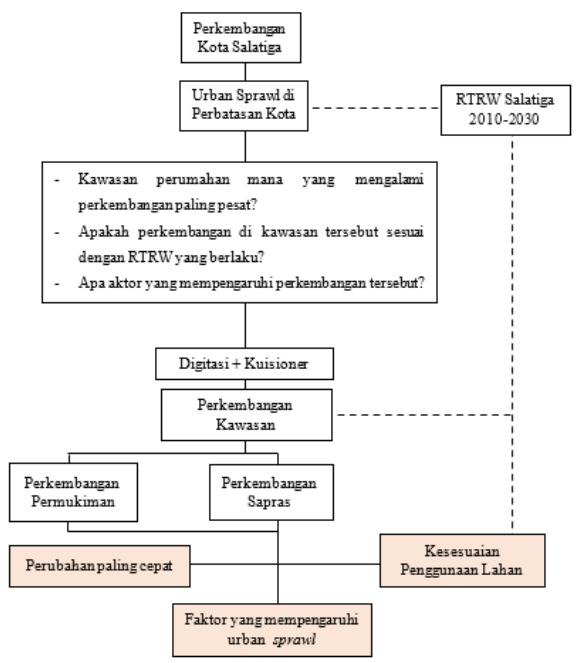

Gambar 3. Alur Pikir Penelitian

Sumber: Analisa Peneliti, 2019

\section{Hasil dan Pembahasan Hasil Dokumentasi dan Analisa}

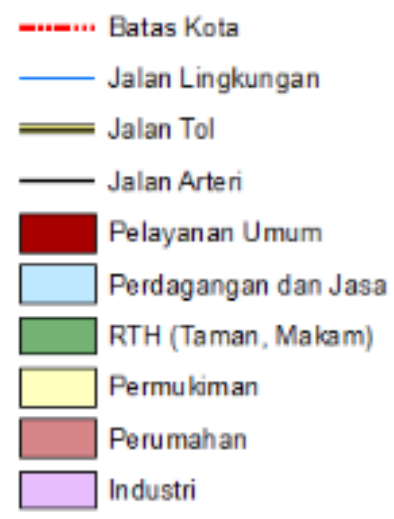

Gambar 4. Keterangan Hasil Digitasi Sumber: Analisa Peneliti, 2019

Keterangan pada gambar hasil digitasi di atas dibagi berdasarkan fasilitas yang mempengaruhi preferensi bermukim penghuni. Penjelasan terkait fasilitas tersebut antara lain, jalan lingkungan merupakan jalan yang berada di area permukiman dan perumahan yang saling menghubungkan. Jalan Arteri merupakan jalan kolektor antar kota. Pelayanan umum mencakup seluruh bangunan seperti tempat ibadah, sekolah, fasilitas kesehatan, fasilitas keamanan, dan bangunan pemerintahan. Sedangkan perdaganan dan jasa mencakup bangunan disektor ekonomi seperti pasar, swalayan, dan toko. Ruang Terbuka Hijau (RTH) berupa taman dan pemakaman. Permukiman mencakup bangunan hunian disekitar perumahan. Perumahan merupakan lokasi sampel yang dipilih dari setiap kecamatan. Industri mencakup bangunan pabrik dari berbagai macam sektor.

\section{A. Perumahan Manunggal 2, Kecamatan Sidorejo (P1)}

Perumahan ini terletak di Kecamatan Sidorejo, tepatnya di Kelurahan Kauman Kidul. Perumahan ini mulai dibangun tahun 2001 dan terus berkembang sesuai kebutuhan penghuni. Bahkan terdapat beberapa cluster perumahan baru yang sekarang masuk dalam satu wilayah. 

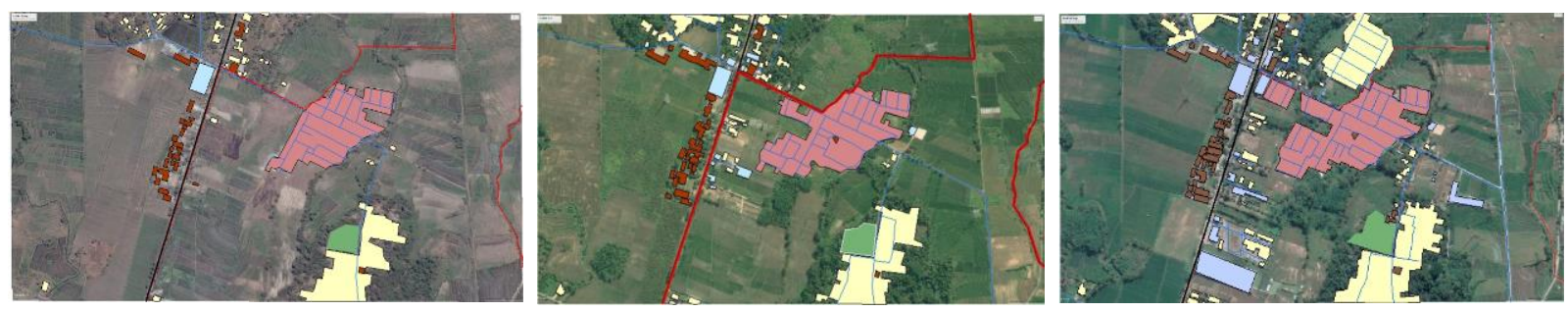

Gambar 5. P1 Tahun 2002 (Kiri), P1 Tahun 2010 (Tengah), P1 Tahun 2019 (Kanan)

Sumber: Analisa Peneliti, 2019

Tahun 2002 fasilitas perdagangan berupa pasar, pelayanan umum sudah memadai (Gambar 5, kiri) meskipun fasilitas tersebut milik kabupaten bukan kota. Permukiman dan perumahan Manunggal 2 masih tergolong kepadatan rendah. Pada tahun 2010, fasilitas perdagangan mulai bertambah (Gambar 5, tengah). Permukiman bertambah padat tapi tidak meluas. Perumahan Manunggal 2 bertambah padat dan luas. Akses jalan lingkungan di perumahan dan permukiman diperbaiki. Jalan arteri diperlebar. Sedangkan pada tahun 2019, fasilitas perdagangan dan jasa bertambah banyak, permukiman juga bertambah padat. Ada permukiman baru yang dibangun di kawasan tersebut (Gambar 5, kanan), sedangkan wilayah perumahan Manunggal 2 mengalami perluasan. Infrastruktur jalan arteri sudah diperbaiki dan titik ini dekat dengan tol Solo-Semarang.

\section{B. Perumahan PNS Prajamukti, Kecamatan Sidomukti (P2)}

Letak perumahan ini di Kelurahan Kecandran, merupakan perumahan bersubsidi yang awalnya diperuntukan untuk PNS. Perumahan ini sudah mulai dihuni tahun 2015. Sampai sekarang fasilitas taman ada yang belum terbangun karena dana digunakan untuk menyelesaikan perumahan PNS Prajamulya (P3).
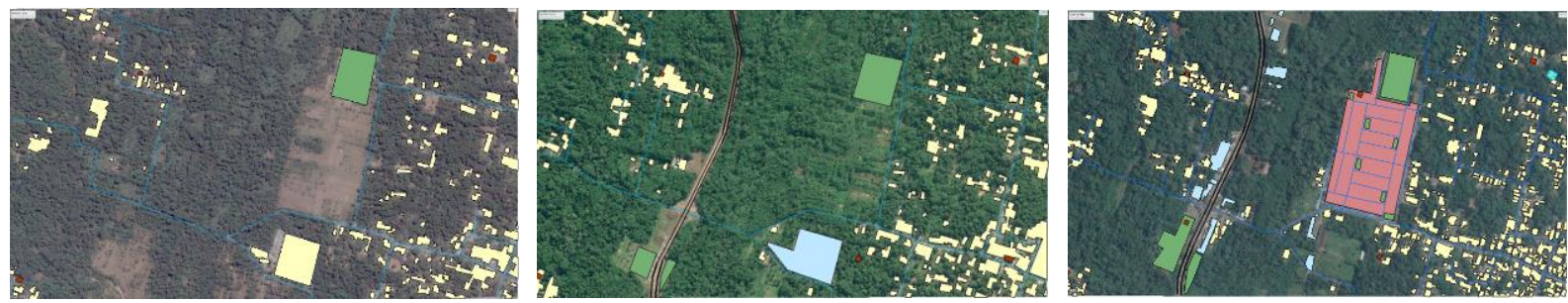

Gambar 6. P2 Tahun 2002 (Kiri), P2 Tahun 2010 (Tengah), P2 Tahun 2019 (Kanan)

Sumber: Analisa Peneliti, 2019

Perumahan PNS Prajamukti belum terbangun pada tahun 2002 (Gambar 6, kiri). Kawasan masih berupa permukiman kepadatan rendah dan pelayanan umum berupa tempat ibadah. Pada tahun 2010 Jalan Lingkar Selatan (JLS) sudah dibangun. Perumahan PNS Prajamukti belum terbangun di tahun ini (Gambar 6, tengah). Permukiman bertambah padat tapi tidak signifikan. Terdapat penambahan fasilitas berupa makam. Pada tahun 2019, fasilitas perdagangan dan jasa bertambah, khususnya di pinggir JLS (Gambar 6, kanan). Permukiman semakin padat dan jalan lingkungan semakin lebar. Fasilitas makam diperluas. Serta perumahan PNS Prajamukti sudah terbangun meski belum padat dan terdapat sarana RTH berupa taman.

\section{Perumahan PNS Prajamulya, Kecamatan Argomulyo (P3)}

Sama seperti Perumahan PNS Prajamulya, perumahan ini juga merupakan proyek subsidi perumahan dari pemerintah. Lokasinya berada di Kelurahan Randuacir, di perumahan ini masih banyak tanah yang belum terkelola. 

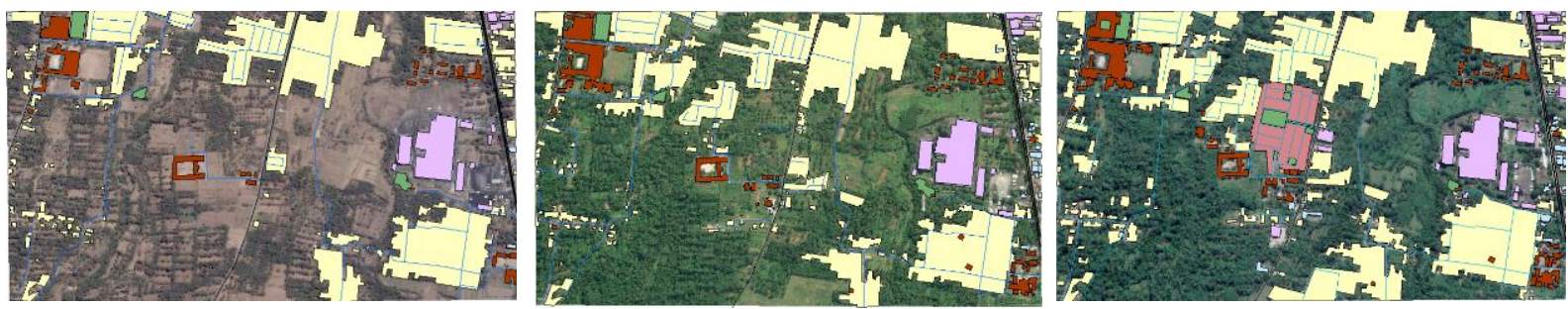

Gambar 7. P3 Tahun 2002 (Kiri), P3 Tahun 2010 (Tengah), P3 Tahun 2019 (Kanan)

Sumber: Analisa Peneliti, 2019

Perumahan PNS Prajamulya di titik P3 belum terbangun pada tahun 2002 (Gambar 7, kiri), namun perumahan lain sudah ada membentuk permukiman yang belum padat. Fasilitas pelayanan umum masih sedikit dan jalan lingkungan belum meluas. Titik ini dekat dengan kawasan industri dan jalan arteri provinsi. Pada tahun 2010 (Gambar 7, tengah) permukiman baru mulai muncul dan menyebar, namun perumahan PNS Prajamulya di titik P3 belum terbangun meskipun dekat dengan JLS. Pelayanan umum mengalami perluasan dan jalan lingkungan bertambah. Sedangkan pada tahun 2019 (Gambar 7, kanan) Perumahan PNS Prajamulya sudah terbangun dengan kepadatan masih rendah. Mulai muncul kawasan industri disekitar perumahan. Permukiman semakin padat dan mulai menyebar permukiman kecil. Infrastruktur jalan lingkungan bertambah semakin banyak dan lebar.

\section{Perumahan Taman Mutiara, Kecamatan Tingkir (P4)}

Berada di Kelurahan Tingkir Tengah, dan dekat perbatasan kota. Perumahan ini mulai terhuni sejak tahun 2010, letaknya sedikit menjorok dari jalan arteri, di tengah sawah.
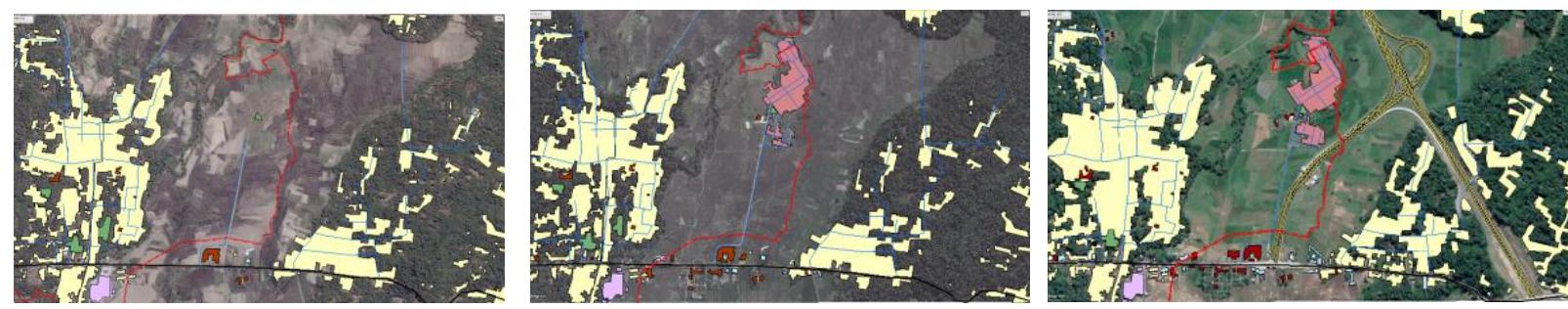

Gambar 8. P4 Tahun 2002 (Kiri), P4 Tahun 2012 (Tengah), P4 Tahun 2019 (Kanan)

Sumber: Analisa Peneliti, 2019

Tahun 2002 Perumahan Taman Mutiara di titik P4 belum terbangun (Gambar 8, kiri), namun sudah ada permukiman dengan kepadatan rendah. Jalan arteri penghubung kota dan kabupaten sudah ada. Pelayanan umum masih berupa tempat ibadah dan sekolah. Untuk perdagangan dan jasa belum banyak pada tahun ini. RTH masih berupa pemakaman mesik sudah ada industri di kawasan ini. Pada tahun 2012 (Gambar 8, tengah) perumahan Taman Mutiara sudah terbangun dan memiliki kepadatan yang sedang. Permukiman disekitarnya juga bertambah padat dari rendah ke sedang. Pelayanan umum bertambah, seperti SPBU dan kantor BBI Salatiga. Jalan lingkungan baru bertambah di perumahan Taman Mutiara. Kemudian tahun 2019 (Gambar 8, kanan) Jalan Tol Solo-Semarang sudah beroperasi. Perumahan Taman Mutiara dan permukiman berkembang menjadi kawasan yang padat hunian. Pelayanan umum dan perdagangan jasa juga kian bertambah di sepanjang jalan arteri Suruh-Salatiga. 


\section{Hasil Kuesioner}

\section{A. Identitas Penghuni}

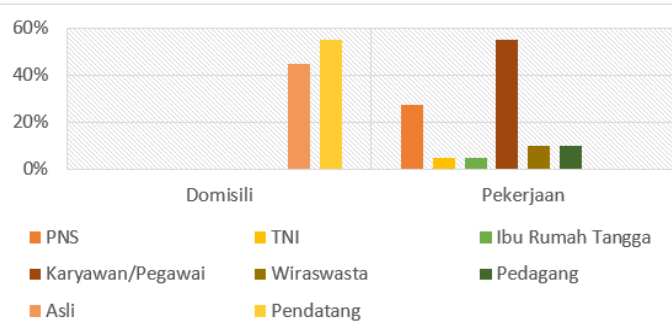

Gambar 9. Presentase Domisili Dan Pekerjaan Penghuni Sumber: Analisa Peneliti, 2019

Hasil kuesioner terkait identitas penghuni adalah, 55\% merupakan pendatang dengan latar belakang pekerjaan yang beragam, seperti PNS, TNI, karyawan, wiraswasta, ibu rumah tangga, dan pedagang. Presentase pekerjaan paling tinggi yaitu karyawan/pegawai sebanyak 55\%, yang kebanyakan bekerja di luar kota khususnya Kabupaten Semarang.

\section{B. Fasilitas yang Mempengaruhi Penghuni}

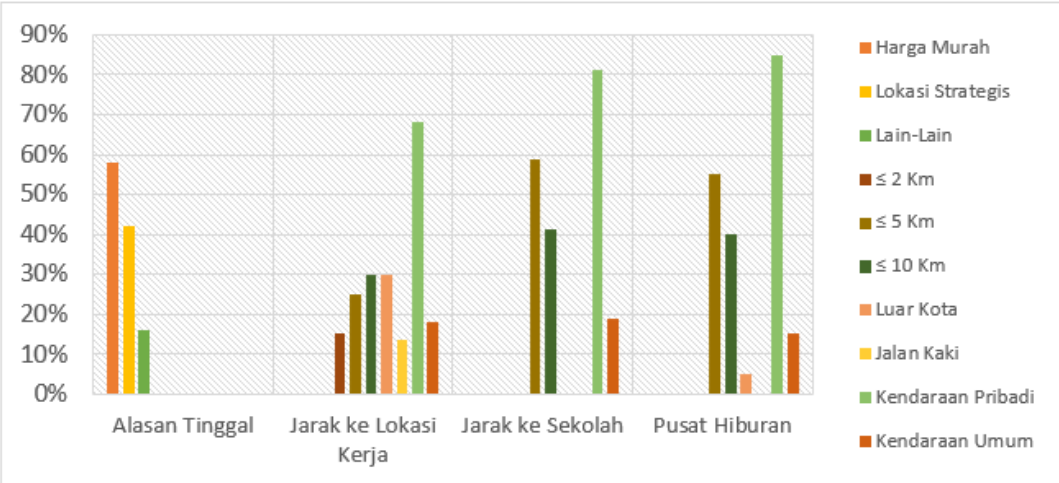

Gambar 10. Fasilitas Yang Mempengaruhi Penghuni Sumber: Analisa Peneliti, 2019

Berdasarkan hasil presentase faktor umum preferensi penghuni untuk tinggal di perumahan tersebut adalah harga yang murah yaitu sebanyak 58\%. Jarak ke lokasi pekerjaan berdasarkan hasil presentase cukup jauh, yaitu $\leq 10 \mathrm{~km}$ hingga ke luar kota. Sedangkan jarak ke sekolah dan pusat hiburan relatif dekat yaitu $\leq 5 \mathrm{~km}$. Untuk moda transportasi, kebanyakan menggunakan kendaraan pribadi daripada kendaraan umum. 


\section{Faktor Kenyamanan dan Keluhan Penghuni}

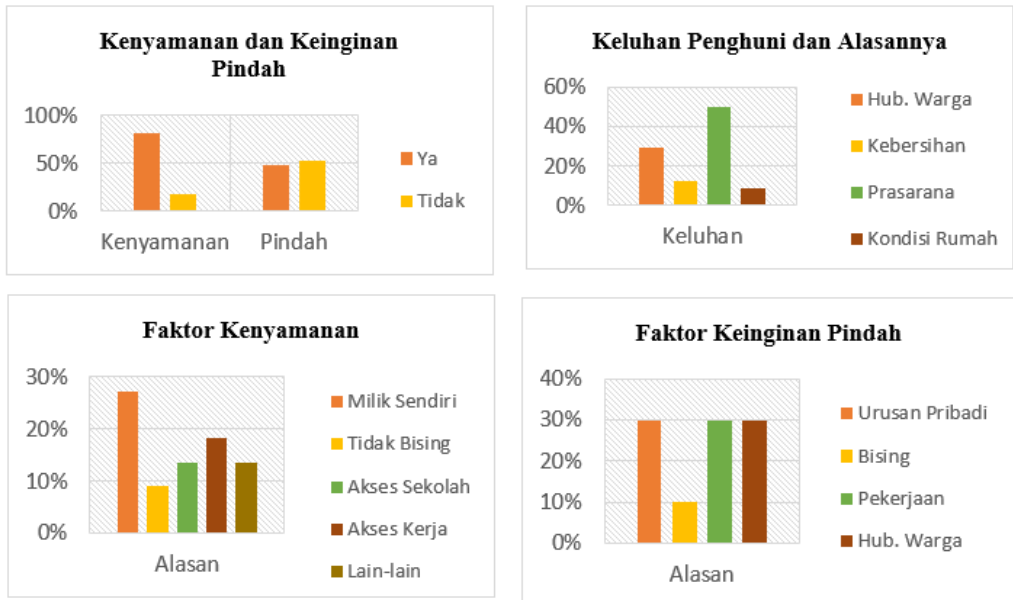

Gambar 11. Fasilitas Kenyamanan Dan Keluhan Penghuni Sumber: Analisa Peneliti, 2019

Hasil kuesioner terkait dengan kenyamanan penghuni, sebanyak $81 \%$ menyatakan nyaman tinggal di perumahan tersebut. Faktor yang paling banyak yaitu karena rumah sudah milik sendiri, sehingga tidak perlu lagi pindah dan mencari hunian baru. Sedangkan $48 \%$ penghuni merasa ingin pindah dari perumahan tersebut dikarenakan beberapa faktor. Faktor yang paling dominan ada tiga yaitu urusan pribadi, masalah pekerjaan, dan hubungan dengan warga atau tetangga.

\section{Pembahasan}

\section{A. Titik dengan Perubahan Paling Cepat}

Data digitasi menunjukkan hasil pemetaan kawasan yang berkembang dengan pola beragam di setiap titik. Berikut merupakan peta perkembangan dalam skala kota:
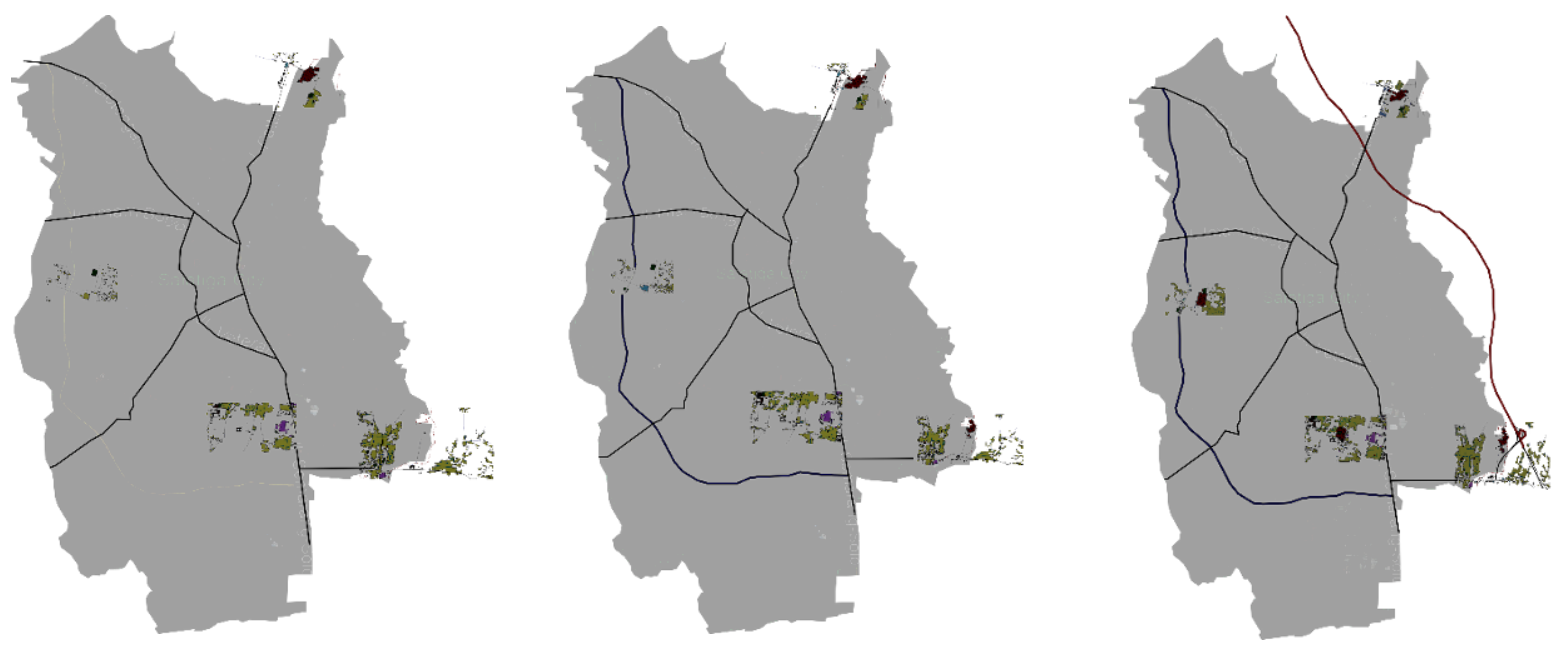

Gambar 12. Perkembangan Kota Tahun 2002 (Kiri), 2010 (Tengah), Dan 2019 (Kanan)

Sumber: Analisa Peneliti, 2019

Berdasarkan Gambar 12 dapat dilihat bahwa perkembangan paling pesat yang berpotensi menimbulkan sprawl adalah titik P3. Titik ini dekat dengan pelayanan umum, dilalui jalur angkutan kota, dan dekat dengan JLS. Sejalan dengan penjelasan Drabkin (dalam Paruntung, 
2004) tentang faktor yang mempengaruhi individu dalam memilih hunian yaitu: aksesibilitas, dalam kemudahan mencapai pusat kota; lingkungan, berupa tidak bising atau kenyamanan lingkungan; dan fasilitas pelayanan, berupa ketersediaan sarana dan prasarana. Sedangkan titik yang sangat mengalami pertumbuhan secara cepat selanjutnya yaitu P1 dan P4. Hasil kuesioner menunjukkan preferensi bermukim paling banyak berdasarkan pada alasan harga murah, sedangkan faktor kenyamanan bermukim adalah kepemilikan rumah yang legal.

\section{B. Kesesuaian Penggunaan Lahan}

Perkembangan kota yang cepat sangat memungkinkan perubahan lahan yang tidak sesuai dengan RTRW yang sedang berlaku. Maka perlu dilakukan evaluasi terkait perkembangan tiap titik dengan RTRW Kota Salatiga Tahun 2010-2030. Berdasarkan hasil amatan, titik yang tidak sesuai peruntukannya yaitu P1 dan P2. Untuk titik P1, ketidaksesuaian terjadi di sepanjang jalan kolektor dengan munculnya permukiman baru yang seharusnya merupakan kawasan perdagangan dan jasa. Sedangkan untuk titik perumahan P2 seharusnya adalah zona pertanian kering namun sekarang dijadikan permukiman.

\section{Kesimpulan}

Berdasarkan hasil penelitian tentang perkembangan perumahan yang berpotensi menimbulkan urban sprawl di Kota Salatiga ini dapat ditarik simpulan sebagai berikut: Pertama, titik yang mengalami perkembangan paling pesat adalah P3, dengan faktor preferensi bermukim paling banyak dikarenakan perumahan memiliki harga murah, sedangkan faktor kenyamanan bermukim adalah kepemilikan rumah yang legal (sudah milik sendiri). Kedua, ada titik yang sudah sesuai dengan RTRW, yaitu titik P3 dan P4. Titik yang tidak sesuai peruntukannya yaitu P1 dan P2. Untuk titik P1, ketidaksesuaian terjadi dengan munculnya permukiman baru pada zona perdagangan dan jasa. Sedangkan untuk titik perumahan P2 seharusnya lahan perumahan adalah zona pertanian kering. Ketiga, berdasarkan hasil analisa faktor penyebab sprawl di titik dengan perkembangan paling pesat (P3) yang memungkinkan terjadinya urban sprawl di masa datang adalah berkembangnya infrastruktur yang semakin baik, dekat dengan fasilitas pelayanan umum seperti sekolah, kesehatan, keamanan, hiburan dan kemudahan aksesibilitas berupa jalur angkutan umum.

Hasil penelitian ini tentu masih memerlukan kajian lebih mendalam, untuk itu peneliti ingin memberikan saran kepada beberapa pihak yang terkait dengan hasil penelitian ini, diantaranya: Pertama, pengawasan terhadap pembangunan di perbatasan kota oleh pihak pemerintah lebih diperketat agar tidak memunculkan potensi urban sprawl dikemudian hari. Sehingga terjadi pemerataan ekonomi dan terjaganya daerah rural dalam kota. Kedua, peningkatan moda transportasi dalam kota sehingga bisa menurunkan ketergantungan akan kendaraan pribadi untuk mengurangi dampak kemacetan di masa datang. Ketiga, masyarakat selaku penghuni perumahan untuk selalu menjaga hubungan sosial dan fasilitas lingkungan agar terciptanya kenyamanan bersama.

\section{Daftar Pustaka}

Apriani, V. I., \& Asnawi. (2015). Tipologi Tingkat Urban Sprawl di Kota Semarang Bagian Selatan. Jurnal Teknik PWK, 4 (3), 405 - 416. Retrieved from s1.undip.ac.id/index.php/pwk

Budihardjo, E., \& Sujarto, D. (2009). Kota Berkelanjutan (Sustainable City). Bandung: P.T. Alumni.

Christiansen, P., \& Loftsgarden, T. (2011). Drivers behind urban sprawl in Europe. TØI report, 1136, 7-23. Retrieved from https://www.toi.no/getfile.php/1317329-
1303822159/Publikasjoner/TØI\%20rapporter/20 11/1136-2011/1136-2011-el.pdf

Darjosanjoto, E. T. (2006). Penelitian Arsitektur di Bidang Perumahan dan Permukiman. Surabaya: ITS press

Hardari, P. (2011). Transformasi wilayah peri urban. kasus di Kabupaten Semarang. Jurnal Geografi, 8(2), 108-117. https://doi.org/10.15294/jg.v8i2.1661

Kharisma, E. C. P., Yudana, G., \& Astuti, W. (2017). Pengaruh Faktor Preferensi Bermukim Masyarakat Dalam Memilih Hunian Perumahan 
Terhadap Kondisi Fisik Lingkungan Di Pinggiran Selatan Kota Surakarta. ARSITEKTURA Jurnal Ilmiah Arsitektur dan Lingkungn Binaan, 15(1), 156164. https://doi.org/10.20961/arst.v15i1.11646

Krismanto, K. (2018, Januari 5) Peran Arsitek dalam Mengembangkan Wajah Kota. IAI Jakarta. Retrieved from https://iaijakarta.org/pustaka/lihat/peran-arsitek-dalammengembangkan-wajah-kota

Muthmainnah, A. (2018). Keterkaitan Kondisi Fasilitas Taman Kota dengan Minat Pengunjung (Kasus: Taman Lembah Mawar dan Gurame, Depok). Surakarta: Universitas Muhammadiyah Surakarta.

Paruntung, M. (2004). Faktor-faktor yang mempengaruhi pemilihan lokasi perumahan perumnas IV Padang Bulan Kota Jayapura. Semarang: Magister Pembangunan
Wilayah dan Kota, Fakultas Teknik Universitas Diponegoro.

Rafferty, J. P. (2019, Februari 7). Urban Sprawl. Encyclopedia Britannica. Retrieved from https://www.britannica.com/topic/urbansprawl

Turner, John, F. C. (1977). Housing by people: Towards Autonomy in Building Environment. New York: Pantheon Books.

Widiawaty, M. A., Dede, M., \& Ismail, A. (2019). Analisis Tipologi Urban Sprawl di Kota Bandung Menggunakan Sistem Informasi Geografis. Prosiding Seminar Nasional Geomatika, 3, 547-554 https://doi.org/10.24895/SNG.2018.3-0.1007

Zahnd, M. (2006). Perancangan Kota Secara Terpadu: Teori Perancangan Kota dan Penerapannya. Yogyakarta: Penerbit Kanisius. 